\title{
Preparing Business Students for the World of Work—-Games for Intercultural Skill Development
}

\author{
Maureen Snow Andrade ${ }^{1, *}$ \\ ${ }^{1}$ Department of Organizational Leadership, Utah Valley University, Orem, UT, United States \\ *Correspondence: Maureen Snow Andrade, Department of Organizational Leadership, Utah Valley University, 800 \\ W. University Parkway MS 205, Orem, UT. 84058, USA. Tel: 1-801-863-5917. E-mail: maureen.andrade@uvu.edu
}

Received: October 13, 2021

Accepted: November 13, $2021 \quad$ Online Published: November 20, 2021

doi:10.5430/jct.v10n4p91

URL: https://doi.org/10.5430/jct.v10n4p91

\begin{abstract}
Most work environments today are diverse - gender, age, culture, language, values, ethnicity. Businesses are also increasing their global presence with branches in international locations and daily interactions across countries and cultures, all made easier through technological advances. Business education must be at the forefront in preparing students to work effectively in these contexts, and in particular, help future managers develop the skills to establish high performing diverse teams within and across organizations. A number of pedagogical approaches can be implemented in business courses to help students develop intercultural competencies. Three games for engaging students in the recognition and appreciation of cultural differences are described in this article. Ideas for debriefing are provided as well as for analyzing learning outcomes. The purpose of this article is to share strategies and approaches for implementing intercultural development pedagogies and measuring their effectiveness.
\end{abstract}

Keywords: management education, diversity, intercultural skills, global competence, high impact practices, $21^{\text {st }}$ century skills, high impact practices

\section{Introduction}

\subsection{A Global Workplace}

Megatrends in the world of work, specifically "digital transformation, globalisation and demographic changes - are shaping skills demand through the creation and destruction of jobs as well as the changing nature of existing occupations" (International Labour Office and the Organisation for Economic Co-operation and Development, 2018, p. 1). As such, recent higher education graduates are more likely to change jobs, positions, and locations than those in the past. Their record of long-term employment is considerably less compared to previous generations, an average of 3.2 years compared to 10.3 years for employees over the age of 55 (U.S. Department of Labor Statistics, 2013).

In today's global society, intercultural skills are not just an advantage but an essential professional skill. International companies expect employees to be flexible in terms of accepting overseas assignments or working in global teams, and to be prepared with the skills to be effective in these environments. Technical skills can be learned on the job; cross-cutting skills such as intercultural competence - critical in both domestic and international contexts-impact an employee's ability to adapt and be productive (CurrencyFair, 2017). In short, intercultural competence is an important 21 st century skill, reflecting citizenship, collaboration, resilience, and adaptability (Advance HE, 2019). It involves awareness of one's reactions to differences, knowledge of one's own values and beliefs, and understanding and respect for the values and behaviors of others (Alpert, 2018).

\subsection{The Need for Intercultural Skills}

Intercultural skills entail not only those relevant to working in international locations, but also the ability to communicate with and respect diversity within a company (co-workers and customers). To prepare students for these contexts, many universities in the United States have a global or intercultural requirement aimed at helping students analyze global issues, address stereotypes, recognize their own cultural values, and interact with those different from themselves. These requirements may be a course or a choice of courses or integrated into the curriculum within a program of study. 
Indeed, such requirements reflect high impact practices, defined as interventions to improve student success, as evidenced "by academic achievement, engagement in educationally purposeful activities, satisfaction, persistence, attainment of educational objectives, and acquisition of desired learning outcomes that prepare one to live an economically self-sufficient, civically responsible, and rewarding life" (Kuh, O'Donnell, \& Schneider, 2017, p. 9). In particular, the high impact practice identified as diversity, is described as follows:

Many colleges and universities now emphasize courses and programs that help students explore cultures, life experiences, and worldviews different from their own. These studies - which may address US diversity, world cultures, or both - often explore "difficult differences" such as racial, ethnic, and gender inequality, or continuing struggles around the globe for human rights, freedom, and power. Frequently, intercultural studies are augmented by experiential learning in the community and/or by study abroad (AAC\&U, 2019, para. 9).

Intercultural competence has been defined as the "knowledge and ability to successfully deal with intercultural encounters" (Matveev \& Merz, 2014). Scholars distinguish intercultural competence from intercultural sensitivity with the former reflecting "the ability to think and act in interculturally appropriate ways" (Hammer, Bennet, \& Wiseman, 2003, p. 422) and the latter as "the ability to discriminate and experience relevant cultural differences" (Hammer et al., 2003, p. 422). A number of frameworks have been proposed to describe the components of intercultural competence, such as Deardorff's (2010) research-based intercultural competence model. The five aspects of the model include attitudes (e.g., respect, openness, curiosity, discovery); knowledge (e.g., cultural self-awareness, culture-specific knowledge, and understanding others' perspectives; skills such as observing, listening, analyzing, and interpreting; internal outcomes, including the ability to adapt, empathize, and respond to others in culturally appropriate ways; and external outcomes exhibited through effective and appropriate behavior (Deardorff, 2010).

The responsibility to help future employees and managers develop intercultural competencies can be daunting, particularly as the development of these competencies is viewed as an on-going developmental process (Deardorff, 2009). However, a variety of games can be implemented with the goal of simulating an intercultural context. These games are enhanced by the diversity inherent in most college classrooms, which make the experiences richer due to the differing perspectives, reactions, and insights of the students, who may represent a range of cultures or who have experienced other cultures. The use of such games can help students begin to develop the attitudes, knowledge, and skills needs to realize the internal and external outcomes identified by Deardorff's intercultural competence model (2010).

\section{Games as a Pedagogical Tool}

Games in the higher education classroom involve card games, simulations, case studies, game show re-enactments, or other formats with the goal of interaction and active learning. They encourage content acquisition and motivation (Connolly, Boyle, MacArthur, Hainey, \& Boyle, 2012), and break up the monotony of class lectures and other traditional teaching pedagogies. They address classroom disengagement and encourage creativity, contentment, awe and wonder, excitement, and curiosity, among other emotions (McGonigal, 2011), all of which help lower affective barriers to learning, help students relax, get to know each other, and have fun.

Games that help students acquire intercultural skills are typically short-term-engaging students in an activity within one or two class sessions. Designed to simulate an experience that students might have in an intercultural context or by observing such a context, they can encourage reflection on intercultural issues and the identification of general principles. Three examples follow.

\subsection{BARNGA}

Barnga is a well-known cross-cultural simulation game, developed by Thiagarajan and Thiagarajan (2006), with many adaptations readily at hand through an internet search. Students are divided into groups and given a set of rules for playing the game; however, each group has a slightly different set of rules. As the winners of each round form new groups, conflict ensues and must be overcome only through non-verbal communication such as gestures and drawing. At the end of the game, the players return to their home group to debrief. The instructor helps students draw analogies to learning the norms and behaviors of their own cultures and having these challenged when they immerse themselves in a different culture.

To encourage students to synthesize their learning and also to assess students' learning, instructors can use a number of strategies for debriefing. These should focus on helping students reflect on the experience, recognize similar situations they have experienced, and know how to apply the lessons learned to other situations. A series of guiding 
questions can be followed for this purpose. The instructor can lead a whole class discussion based on these questions or ask students to discuss the questions in small groups. Students can also be given a follow-up reflective writing assignment about their learning. Table 1 provides some possible questions, which can also be used as writing prompts.

Table 1. BARNA Debriefing Questions

\begin{tabular}{|c|c|c|}
\hline Reflect & Recognize & Apply \\
\hline $\begin{array}{l}\text { What was your overall experience } \\
\text { playing the game? What stood out? }\end{array}$ & $\begin{array}{l}\text { What situations have you been in where } \\
\text { you acted differently from others? What } \\
\text { did you do? }\end{array}$ & $\begin{array}{l}\text { What general conclusions can you draw } \\
\text { from this activity? }\end{array}$ \\
\hline $\begin{array}{l}\text { What were your expectations about the } \\
\text { game? }\end{array}$ & $\begin{array}{l}\text { Have you experienced being in a } \\
\text { situation where your views were the } \\
\text { opposite of someone else's? How did } \\
\text { you handle this? }\end{array}$ & $\begin{array}{l}\text { What ar } \\
\text { you are } t\end{array}$ \\
\hline $\begin{array}{l}\text { How did you feel when you were } \\
\text { playing with your home team compared } \\
\text { to playing with a new team? }\end{array}$ & $\begin{array}{l}\text { Have you visited or lived in another } \\
\text { country or experienced a different } \\
\text { culture? Have you ever felt like an } \\
\text { outsider? }\end{array}$ & $\begin{array}{l}\text { How can you apply these principles to } \\
\text { other situations? In your personal lives? } \\
\text { In the workplace? }\end{array}$ \\
\hline $\begin{array}{l}\text { How did the limitations on } \\
\text { communication impact your } \\
\text { experience? What did you do to } \\
\text { communicate? }\end{array}$ & $\begin{array}{l}\text { How have you navigated cultural } \\
\text { differences? What can you do to } \\
\text { understand what drives behaviors and } \\
\text { what underlying values might be } \\
\text { represented by behaviors? }\end{array}$ & $\begin{array}{l}\text { Do you anticipate working in a global } \\
\text { context in the future? What strategies } \\
\text { might you consider to help you be } \\
\text { successful in this context? }\end{array}$ \\
\hline $\begin{array}{l}\text { What did you do when you realized the } \\
\text { rules were different? How did you } \\
\text { react? What did you change? }\end{array}$ & $\begin{array}{l}\text { How aware are you of your own culture } \\
\text { and why you behave in certain ways? } \\
\text { How did you learn these behaviors? }\end{array}$ & $\begin{array}{l}\text { What can you do to prepare for working } \\
\text { with people from different cultural, } \\
\text { linguistic, or ethnic backgrounds? }\end{array}$ \\
\hline $\begin{array}{l}\text { What analogies can you make between } \\
\text { the game and real-life? }\end{array}$ & $\begin{array}{l}\text { Do you seek friends or associates who } \\
\text { are similar to or different from } \\
\text { yourself? }\end{array}$ & $\begin{array}{l}\text { What can you do to better understand } \\
\text { yourself and your personal and cultural } \\
\text { values? Why is this important? }\end{array}$ \\
\hline
\end{tabular}

From this discussion, some general principles can be drawn such as:

- We learn behaviors, habits, and norms, and form expectations about how others should behave from our home environments. We learn cultural behaviors from our parents, family members, and others with whom we associate.

- These behaviors and norms become set and we perform them instinctively. We may be unaware of our own behaviors and norms or not realize that they vary across individuals, peoples, and cultures until we encounter people who exhibit different behaviors. We may not recognize the underlying values or reasons for these behaviors.

For more details about Barnga, including step-by-step instructions for playing, rule templates to distribute to participants, and variations for the game, consult Thiagarajan and Thiagarajan (2006), go to http://www.acphd.org/media/271383/barnga_instructions.pdf or https://sites.lsa.umich.edu/inclusive-teaching/wp-content/uploads/sites/355/2017/07/Barnga-Card-Game-Rules-1.pdf, or conduct an internet search with the key word BARNGA.

\subsection{Cocktail Party}

The cocktail party activity was designed for those training to be hospitality managers but has broad application to a variety of workplace roles (Jameson, 2007). Participants are grouped into three teams of managers, each representing a different culture. They receive an instruction sheet with information about their culture and are given time to review this information and practice culture-appropriate behaviors. The three groups then come together at a cocktail party, which is the opening event for a series of meetings to discuss a joint business venture. At the party, participants 
exhibit the behaviors representative of their culture and experience the cultures of the other groups. This is followed by a discussion of observations. A number of variations of this activity are available and instructors are encouraged to adapt it to fit their specific course objectives.

\subsubsection{Preparation}

The cocktail party simulation involves some preparation and planning. Details and handouts for the activity are available

https://scholarship.sha.cornell.edu/cgi/viewcontent.cgi?referer=https://www.google.com/\&httpsredir=1\&article=100 $4 \&$ context $=$ chrtools. Table 2 provides an overview of the items needed and specifics related to conducting the activity.

Table 2. Cocktail Party Preparation

\begin{tabular}{lll}
\hline Item & Description or Details & Instructions \\
\hline Leader directions & Leader directions provide information Leader directions are distributed after \\
& about how to help company the instructor provides instructions \\
& representatives prepare for the cocktail about the simulation and when students \\
& party. Leaders will discuss the culture's are divided into groups Full \\
& beliefs, values, and behaviors (based on descriptions and handouts are available \\
& a culture information sheet for each in Jameson, 2007.
\end{tabular}

group) and how to manifest these at the party. They will discuss what they want to accomplish at the party related to their role in the joint venture and in the initial interaction with the other companies. Groups should also practice the cultural behaviors they will use at the party by role-playing. Ideally, groups should have separate locations in which to meet to discuss and practice their cultural behaviors.

Information sheet about cultural Brief overview-

behaviors and values for each team.

Name tags with colors representing each culture - red, green, and blue. Markers to write on the name tags.

Refreshments, plates, cups, utensils

Instructor role
Refreshments can be simple but should include items that members of the red culture cannot eat such as raw vegetables or fruits.
Red - task-oriented, do not waste time, do not eat uncooked food

Green - conservative, members of a religious sect, pray frequently

Blue - congenial, friendly, use physical contact

Students will complete their name tags when they arrive at the cocktail party.

Cultural information sheets should be distributed to students by their leaders or by the instructor when students are divided into their culture groups. Full culture descriptions and handouts are available in Jameson, 2007.

Instructors should appoint a host culture to greet guests and invite them to wear a name tag. Members of the blue culture often serve as hosts due to their outgoing nature.

Refreshment stations can be distributed around the room to encourage groups to form and interact.

Instructors should observe student behaviors during the party but not be directly involved. Let the party progress on its own and give students time to interact. Observations made during the party can be used in the debriefing. 


\subsubsection{Debriefing}

The debriefing session for this activity seldom fails to invite enthusiastic response and wide contribution of observations and comments from students. Instructors can begin the discussion by creating three columns on the board, one for each culture. They can then ask for an outside view of what students observed in their interactions with members of the other cultures (color groups). For example, they can ask the blue and red culture groups to share what they experienced from interacting with members of the green culture and write the comments on the board. Then they ask the green culture to explain what is behind this behavior; in other words, ask them to identify the values and beliefs that shape their behaviors (this information is available on the information sheets for the most part).

For example, members of the red and blue cultures often make observations about how the green culture members treated women at the party and how members from that culture tried to separate themselves from the women. The green culture members then explain that in their culture they believe men to be superior to women and that the sexes should be separated. This belief and resulting behavior often cause conflict, which the red and blue cultures try to address in various ways during the party. Other examples might be related to physical distance when conversing, the use of physical contact, or levels of formality in forms of address. The most insightful part of the discussion is when the reasons for the behaviors - the underlying value - are revealed. Students begin to see that cultures have different ways of showing respect, making decisions, managing conflict, and so on.

The debriefing activity can be accompanied by a discussion of the iceberg analogy where some aspects of a culture are above the surface and readily observable and others are below the surface and hidden (Hall, 1976). Above the surface behaviors include dress styles, eating customs, and manners. Less observable, below the surface, or internal behaviors, involve values, beliefs, and assumptions, as well as preferences and philosophies. Introducing the concepts of surface- and deep-level diversity can also be helpful as part of this discussion. When people experience cultures apart from their own, they initially see the observable or surface-level aspects, but as they spend more time in the culture, they begin to understand the reasons, values, and beliefs underpinning the behaviors. In the cocktail party simulation, behaviors of the different groups take on much more meaning when the reasons for them are explained and students begin to have insights into what is behind cultural differences.

Additional follow-up activities outlined by Jameson (2007) include the following:

1. Organize an additional cocktail party to see how participants interact when they are more knowledgeable about each other's cultures. This helps students understand the need to prepare for cultural interactions and how being well-informed can dramatically change the outcomes of interactions in business and social contexts.

2. Hold a simulated business meeting in which the participants work out details of the joint venture. In this meeting, company representatives will likely encounter a number of areas of disagreement and need to negotiate. Negotiation concepts and skills can be taught in preparation for this activity (e.g., preparation and planning, ground rules, clarification and justification, bargaining and problem-solving, and closure and implementation). Details about company backgrounds, the goals of each company, and the roles of participants can be created by the students.

3. Ask participants to document and reflect on experiences (past or present) when they have interacted with different individuals or groups from other cultures in personal or professional contexts and how they might apply what they have learned from the simulation and debriefing.

\subsection{Rainbow War Jeopardy}

Rainbow War is a 20-minute video developed for the 1986 World's Fair in Vancouver, Canada (Rogers \& BRC Imagination Arts, 1985). It tells the tale of three ethnocentric kingdoms represented by the colors blue, red, and yellow. Each kingdom has distinct values, norms, and behaviors, characterized by central dispositions - arrogance (blue), fear (red), and dominance (yellow). The kingdoms have no contact until a young man invents a flying ring and travels to the other kingdoms. This sparks a forbidden romance as well as cultural conflict resulting in a colorful paint war resulting in the creation of new colors, increased appreciation and understanding, and collaboration to achieve a shared goal.

\subsubsection{Previewing}

To introduce the activity, instructors can lead a class discussion or divide the students into small groups to consider questions such as the following (e.g., see Fujioka, 1999): 
- What different groups (cultural, ethnic, national, racial) are you familiar with or do you belong to? What groups are represented in this university and in this class?

- How do you and others generally relate to people who are in the minority? How do you expect people who look different from yourself to act or behave - differently or similarly to yourself?

- Share an experience with a person from a different culture, race, or ethnicity. What happened? What meaning do you attach to the experience? How do you interpret it?

\subsubsection{Viewing}

While watching the video, students can be asked to take notes with observations about the cultures depicted, the characteristics of the cultures, and the events in the story. General topics or categories could be provided to help guide note-taking (see Table 3). Students could be asked to watch for 3 or 4 of these categories rather than trying to take notes on all of them. Instructors should give students a few minutes to review the items in the guide prior to watching the video.

Table 3. Rainbow War Note-Taking Guide

\begin{tabular}{l} 
Topics \\
\hline Kingdom characteristics - dress, behaviors, lifestyles, \\
technology, weapons \\
How cultural values were taught and propagated \\
Reactions to change or disruption of the status quo \\
Openness to change; generational differences; hierarchical \\
differences (e.g., rulers and people) \\
Barriers that prevent change and unification \\
Motivations of the rulers to go to other kingdoms, how they \\
prepare, what they take with them \\
Symbols (e.g., the yellow queen's dark glasses, the gifts of \\
the blue king offers the yellow queen, the duck, bubbles, \\
rose, paint, colors, body language, the rainbow) \\
Unifying events; who is first and last to join together \\
Deliberate choices and details that contribute to the theme \\
(e.g., types of flying mechanisms, color choices, weapons, \\
who throws paint on whom)
\end{tabular}

\subsubsection{Jeopardy}

A popular game for the business classroom is an adaption of the game show Jeopardy. A template can be created in PowerPoint (see Figure 1) or even drawn on a chalkboard or whiteboard with the purpose of reviewing the themes and concepts in the Rainbow War video. (Various Jeopardy game PowerPoint templates can be downloaded from the internet; see https://www.lifewire.com/free-jeopardy-powerpoint-templates-1358186; detailed directions for creating your own template are available at https://www.ispringsolutions.com/blog/how-to-make-a-jeopardy-game-in-powerpoint; various YouTube videos with directions are also available; see https://youtu.be/OcwADINrLs0.) You may need to experiment a bit to find the resource you prefer, but creating the template is not complicated and once you get the template and question slides set up, you can copy them and change the questions to focus on different content.

If using PowerPoint, the dollar amounts in the template can be hyperlinked to the question slides (see Figure 2) and the animation feature used to show the question and then the answer. A timer can also be embedded in the slide as well as a link to the home page with the game board (See Figure 2). Different colors can be used for the game board categories and the question slides can be similarly color-coded. 


\begin{tabular}{|c|c|c|c|c|}
\hline Actions & Rulers & Cultures & Symbols & Themes \\
\hline$\$ 100$ & $\$ 100$ & $\$ 100$ & $\$ 100$ & $\$ 100$ \\
$\$ 200$ & $\$ 200$ & $\$ 200$ & $\$ 200$ & $\$ 200$ \\
$\$ 300$ & $\$ 300$ & $\$ 300$ & $\$ 300$ & $\$ 300$ \\
$\$ 400$ & $\$ 400$ & $\$ 400$ & $\$ 400$ & $\$ 400$ \\
$\$ 500$ & $\$ 500$ & $\$ 500$ & $\$ 500$ & $\$ 500$ \\
\hline
\end{tabular}

Figure 1. Jeopardy Game Board

\section{- $\$ 100$}

- Enjoyment of art, beauty, and life

- What are the cultural characteristics of the Blue Kingdom?

Figure 2. Question Slide

To review the content of Rainbow War, the instructor can create categories focused on various aspects of the video as shown in Figure 1, with questions worth varying dollar amounts, to check comprehension and critical analysis of the content. Also, with a little ingenuity, the game could be focused on questions that involve applying organizational behavior concepts or theories (or other business concepts) to the themes of the video. These might involve concepts such as sources of power, power tactics, organizational change, organizational culture, or leadership principles relevant to the video content.

Depending on class size, students can be divided into teams of up to 10, but preferably around 6-8. Three teams are manageable. The following directions should be reviewed before beginning the game:

1. Teams need to decide if they are going to take turns answering questions, or if they are going to discuss the questions together and then have one person be the spokesperson.

2. To start, the instructor selects a team who chooses a category and question level.

3. The instructor reads the question. When the instructor stops, the first team who buzzes will answer the question. There is a 10 second time limit to buzz. (Note - inexpensive game buzzers with different sounds can be purchased for this purpose.)

4. The team who answers correctly gets the dollar amount associated with the question added to its score. Any team attempting an answer and getting it incorrect will have the dollar amount deducted from its total score.

5. If a team answers incorrectly, other teams have 10 seconds to buzz if they want to answer the question. The team who answers the question correctly can choose another question after which all teams have 10 seconds to buzz if they want to answer.

6. Teams are eligible to participate in the final Jeopardy question if they have a positive score balance. Teams set a wager for a specific dollar amount that will be added to or deducted from their score depending on their answer. Each team has 30 seconds to write down its answer after which each shows its answer. Scores are adjusted and the winner announced. 
The instructor, an appointed student, or individual teams can keep score during the game. To add to the fun, Jeopardy game show sounds are freely available for download on the internet and can be integrated into a slide in PowerPoint (see https://www.soundboard.com/sb/jeopardy_show_sounds as an example). It is advisable to check all your slides, animations, and sounds prior to class and also make sure that students understand the rules. However, even if things do not go exactly as planned, students will have fun and you will see a completely different side of them.

An advantage of using Jeopardy with the Rainbow War content is that it encourages students' attention while watching the video and is fairly accessible in terms of difficulty, allowing students to feel successful with it. However, any video or content presented in any format (e.g., reading or lecture) can be used for the game.

\subsubsection{Debriefing}

Following the game, key points can be elicited from students and listed on the board or students can be divided into groups and assigned to discuss specific topics in the guide (Table 3) and then present their conclusions to the class. Additional questions might focus on the following:

- What types of events bring people together and unite them (e.g., natural disasters, tragedies)? What events in history or in the news demonstrate this?

- How can barriers that divide people be overcome?

- How do cultural or other types of differences impact the workplace, particularly team effectiveness and organizational performance? As a manager, would you want to create diverse teams or homogenous teams? Why?

- Make a list of the advantages of diversity in the workplace. Identify possible conflicts that might be caused by diversity conflicts and how these could be addressed.

The video can be used on its own or in conjunction with other activities, particularly the cocktail party simulation (the latter also involves the use of color symbols to represent cultures). The film makes a nice wrap-up to that activity. It can also be incorporated into units on diversity or conflict in organizations.

\section{Outcomes}

A variety of ways to measure the outcomes of activities such as the three shared in this article are possible. UNESCO's four pillars of learning could be used as a reflection or assessment framework. The pillars include learning to know, learning to do, learning to live together, and learning to be, defined as follows (Delors, 2013):

- Learning to know - general and in-depth knowledge on a range of topics, critical thinking, independent thinking

- Learning to do - skills and methods for lifelong learning, vocational and technical skills, application of learning, ability to acquire new skills, management and leadership abilities

- Learning to live together - tolerance, interconnection, mutual respect, teamwork, interdependence, social skills, appreciation of diversity, conflict resolution, global understanding

- Learning to be - self-awareness, self-discovery, ownership, self-direction, personal responsibility, goals, creativity, developing one's potential

While learning to live together appears the most applicable to the development of intercultural skills, students need knowledge of other cultures and cultural adjustment strategies, exposure to a variety of worldviews, interactions with people different from themselves, and awareness of cultural values, norms, and behaviors in order to gain the competencies that enable living together. These are all part of learning to know. Similarly, simulations and activities such as those described in this article can help students learn to do-both in terms of expanding their learning strategies and methods and their workplace and managerial skills. Group work and team assignments can also contribute to learning to live together while reflection assignments can contribute to learning to be as students come to understand themselves and others more deeply. Previous research has established the achievement of these outcomes as a result of working with diverse others in the context of an organizational behavior course (Andrade, 2019). These pillars of learning also reflect Deardorff's (2010) intercultural competency model, consisting of attitudes, knowledge, skills, and internal and external outcomes. A few examples of reflection questions based on the pillars of learning are provided in Table 4. 
Table 4. Pillars of Learning Reflection Questions

\begin{tabular}{|c|c|c|c|}
\hline Know & Do & Live Together & $\mathrm{Be}$ \\
\hline $\begin{array}{l}\text { What new knowledge did } \\
\text { you gain from the activity (or } \\
\text { series of activities)? }\end{array}$ & $\begin{array}{l}\text { How did the activities help } \\
\text { you structure your learning } \\
\text { (e.g., guide your thinking or } \\
\text { help you develop new } \\
\text { strategies for learning)? }\end{array}$ & $\begin{array}{l}\text { How did discussions with } \\
\text { other students change your } \\
\text { thinking? How did you react } \\
\text { when you encountered diverse } \\
\text { perspectives? }\end{array}$ & $\begin{array}{l}\text { What new insights do you } \\
\text { have about yourself as a } \\
\text { result of the intercultural } \\
\text { learning activities? }\end{array}$ \\
\hline $\begin{array}{l}\text { What course concepts or } \\
\text { theories are relevant to on } \\
\text { intercultural understanding } \\
\text { and awareness? }\end{array}$ & $\begin{array}{l}\text { What cultural skills did you } \\
\text { learn? How will you } \\
\text { approach cultural differences } \\
\text { in the future? }\end{array}$ & $\begin{array}{l}\text { What did you learn about how } \\
\text { to navigate differences across } \\
\text { cultures? }\end{array}$ & $\begin{array}{l}\text { What goals might you set } \\
\text { related to increasing your } \\
\text { intercultural skills? }\end{array}$ \\
\hline $\begin{array}{l}\text { What did you learn about } \\
\text { diversity, surface- and } \\
\text { deep-level diversity, the } \\
\text { advantages of diversity, how } \\
\text { cultures are learned and } \\
\text { passed on? }\end{array}$ & $\begin{array}{l}\text { What strategies can you use } \\
\text { to overcome barriers or } \\
\text { manage conflict? }\end{array}$ & $\begin{array}{l}\text { How will you prepare for } \\
\text { intercultural interactions in the } \\
\text { future? }\end{array}$ & $\begin{array}{l}\text { What changes might you } \\
\text { want to make in your } \\
\text { personal or professional } \\
\text { life related to what you } \\
\text { learned? }\end{array}$ \\
\hline
\end{tabular}

Perspectives from a number of disciplines lend themselves to helping students increase their knowledge and skills related to intercultural competence. In organizational behavior, for example, students learn about personality, diversity, emotions, communication, conflict, leadership, teamwork, organizational culture, and change. All of these concepts can be embedded into lesson plans and discussions relevant to the three activities in this article. The pillars can be used to guide lesson planning for the activities or a series of activities and can be used as a framework to analyze students' reflections about their learning. Reflections can be assigned on a weekly basis and the content examined at the end of the semester using the pillars as a framework.

\subsection{Learning Outcomes Summary}

The outcomes of the three activities highlighted are various, but include the following:

- An understanding that cultural values are relative rather than shared across people (Jameson, 2007).

- Recognition of the importance of differences that are below the surface (e.g., values, attitudes, beliefs) and how these may be evidenced by manners and behaviors (Jameson, 2007).

- How we are socialised into our own cultures and how ethnocentrism can lead to conflict, fear, isolation, and prejudice.

- How to overcome conflict through collaboration, shared values, and goals.

- Application of lessons learned to past experiences, current interaction within and outside the classroom, and future interactions and professional practice.

- Motivation, active learning, and engagement in the classroom.

Future research studies can be designed to determine the extent to which these outcomes have been achieved. As indicated, assessments such as reflections can be analyzed using intercultural competency frameworks or other guiding frameworks such as UNESCO's pillars of learning. Longitudinal studies that follow students into the workplace to determine their global competencies would also be intriguing but in order for intercultural competence to be achieved, students need extensive on-going opportunities to develop related knowledge, skills, and behaviors over time. Scholars consider the development of intercultural competence to be a lifelong process (Deardorff, 2010).

\section{Caveats and Conclusions}

The three activities highlighted are representative examples of pedagogical approaches for developing intercultural awareness, understanding, and skills. Certainly, longer-term activities can be used in conjunction with these. Consulting projects where students work in diverse teams and partner with community organizations to study and make recommendations on an issue are a means of helping students apply lessons learned to real-life. Assignments can be accompanied by individual and team reflections, which can be represented in an ePortfolio, a collection of 
students' learning — another high impact practice and a way to assess learning (Kuh et al., 2017; Watson, Kuh, Rhodes, Light, \& Chen, 2016).

The purpose of this article was to introduce practical pedagogical tools to help students develop intercultural competencies. The requisite attitudes, knowledge, and skills needed for these competencies to develop take an extended period of time, much longer than a a few class sessions. A number of suggestions have been made for ways to assess the achievement of lesson objectives related to the activities presented as well as ideas for future research. Overall, games for intercultural skill development are a motivating and engaging way to help prepare students for the impact of worldwide megatrends. However, this development must be continued in other learning contexts, including within the workplace.

\section{References}

Advance

HE.

(2019).

$21 s t$

century

https://www.heacademy.ac.uk/knowledge-hub/21st-century-skills

Alpert, R. T. (2018). Cultural diversity in the workplace. Retrieved from $\mathrm{http}: / / \mathrm{www}$.diversityresources.com/cultural-diversity-workplace/

Andrade, M. S. (2019). ePortfolios and online learning: Applying concepts of organizational behavior. International Journal of E-Learning and Distance Education, 34(1), 1-15.

Association of American Colleges \& Universities. (2019). High-impact educational practices: A brief overview. Retrieved from https://www.aacu.org/leap/hips

CurrencyFair. (2018, February 21). Hiring internationally? Look for these 10 skills in your candidates. Retrieved from https://www.currencyfair.com/blog/hiring-internationally-10-vital-skills/

Deardorff, D. K. (2009). The SAGE handbook of intercultural competence. Thousand Oaks, CA: Sage.

Deardorff, D. K. (2010). A comparative analysis and global perspective of regional studies on intercultural competence. Paris: UNESCO.

Delors, J. (2013). The treasure within: Learning to know, learning to do, learning to live together and learning to be. What is the value of that treasure 15 years after its publication? International Review of Education, 59, 319-330. https://doi.org/10.1007/s11159-013-9350-8

Fujioka, K. (1999). Using Rainbow War to raise global awareness. The Language Teacher, 23(2). Retrieved from https://jalt-publications.org/tlt/departments/myshare/articles/2472-using-rainbow-war-raise-global-awareness

Hall, E. T. (1976). Beyond culture. New York: Anchor Books.

International Labour Office and the Organisation for Economic Co-operation and Development. (2018, June). Global skills trends, training needs and lifelong learning strategies for the future of work. Retrieved from https://www.ilo.org/global/about-the-ilo/how-the-ilo-works/multilateral-system/g20/reports/WCMS_646038/lan g--en/index.htm

Jameson, D. A. (2007). Developing hospitality managers' intercultural communication abilities: The cocktail party simulation. Cornell Hospitality Tools, 9, 6-20. Retrieved from https://scholarship.sha.cornell.edu/cgi/viewcontent.cgi?referer=https://www.google.com/\&httpsredir=1\&article $=1004 \&$ context $=$ chrtools

Kuh, G. D. (2008). High-impact educational practices: What they are, who has access to them, and why they matter. Washington, DC: Association of American Colleges \& Universities. Retrieved from https://www.aacu.org/leap/hips

Kuh, G. D., \& O’Donnell, K. (2013). Ensuring quality \& taking high-impact practices to scale. Washington, DC: Association of American Colleges \& Universities.

Kuh, G. D., O'Donnell, K., \& Schneider, C. G. (2017). HIPs at ten. Change: The Magazine of Higher Learning, 49(5), 8-16. https://doi.org/10.1080/00091383.2017.1366805

Matveev, A. V., \& Merz, M. Y. (2014). Intercultural competence assessment: What are its key dimensions across assessment tools? In L. T. B. Jackson, D. Meiring, F. J. R. Van de Vijver, E. S. Idemoudia, \& W. K. Gabrenya Jr. (Eds.), Toward sustainable development through nurturing diversity: Proceedings from the $21^{\text {st }}$ International Congress of the International Association for Cross-Cultural Psychology. Retrieved from 
https://scholarworks.gvsu.edu/cgi/viewcontent.cgi?article=1009\&context=iaccp_papers

Rogers, B., \& BRC Imagination Arts. (1985). Rainbow war. Retrieved from https://rainbowwar.com/

Thiagarajan, S., \& Thiagarajan, R. (2006). Barnga: A simulation game on cultural clashes. Boston, MA: Intercultural Press.

U.S. Department of Labor Statistics. (2013). Tenure of American workers. Retrieved from www.bls.gov/spotlight/2013/tenure/pdf/tenure.pdf

Watson, C. E., Kuh, G. D., Rhodes, T., Light, T. P., \& Chen, H. L. (2016). Editorial: ePortfolios-The eleventh high impact practice. International Journal of ePortfolio, 6(2), 65-69.

\section{Copyrights}

Copyright for this article is retained by the author(s), with first publication rights granted to the journal.

This is an open-access article distributed under the terms and conditions of the Creative Commons Attribution license (http://creativecommons.org/licenses/by/4.0/). 